\title{
DIE FORMULIER VIR DIE BEVESTIGING VAN DIAKENS
}

\section{INLEIDING.}

Daar is al herhaaldelik gevra dat die Formuliere in gebruik in die Kerk opnuut weer hersien moet word of dat desnoods wisselvorme daarvan voorgestel moet word. Wanneer aandag gegee word aan die Formulier vir die bevestiging van Diakens blyk dit dat daar tog rede is vir hierdie versoek. Trouens Prof. A. D. Pont het by geleentheid opgemerk : „Die Formulier opgestel deur 'n onbekende teoloog, laat in die sestiende eeu, en sinsdien in algemene gebruik, is nie in alle opsigte gelukkig nie en dit skep die indruk asof daar heelwat ruimte vir verbetering is". ${ }^{1)}$ In hierdie stuk word egter slegs aandag gegee aan die vraag of die Barmhartigheidsmotiewe in die Skrif verantwoord is in die Bevestigingsformulier.

Die barmhartigheidsdiens van die Kerk moet gesien word in die lig van die feit dat God die Barmhartige is. ") Goed bekend is die tekswoord: „Barmhartig en genadig is die Here, lankmoedig en groot van goedertierenheid" uit Psalm 103:8. In die Ou Testament word die barmhartigheid van God altyd gesien in verband met die verbond wat $\mathrm{Hy}$ met Sy volk gesluit het. ${ }^{3}$ ) Sy barmhartigheid bestaan in Sy trou teenoor die volk (soos dit veral ook besing word in die Psalm en Lukas 1). Die barmhartigheid van God het tot volle openbaring gekom in Jesus Christus. Brunner ${ }^{4}$ ) stel dit so : „Ein für allemal hat sich Gott in der Menschwerdung seines Sohnes, im Leben, Leiden, Sterben und Auferstehen Jesus Christi als der heilige und der barmherzige geoffenbart." Die Nederlandse Geloofsbelydenis Artikel 20 verklaar: „Ons glo dat God, wat volkome barmhartig en regverdig is .... Sy goedheid en barmhartigheid oor ons wat skuldig en doemwaardig was uitgestort, deurdat $\mathrm{Hy}$ Sy Seun vir ons in die dood gegee het". God bewys Sy barmhartigheid in Jesus Christus. Die slotgebed in die formulier om die heilige Nagmaal te hou, bring dit sterk na vore : „O Almagtige, barmhartige God en Vader, ons dank $u$ dat $u$ uit grondelose barmhartigheid $U$ eniggebore Seun aan ons as 'n Middelaar en offer vir ons sondes en as spys en drank van die ewige lewe geskenk het ...." God is ryk in barmhartigheid en dit het heilshistoriese betekenis gekry.

1. Lesing oor die Amp van die Diaken gehou voor die Vergadering van Diakens van die Ring van Rustenburg 12 Mei 1964.

2. Vergelyk bv. Luk. 1:50, 6:36, Ef. 2:4 en Heb. 2:17.

3. E. Jacob, Theology of the Old Testament, London, 1959, p. 104, Vgl. ook bv. Deut. 4:31; II Kron. 30:9.

4. E. Brunner, Offenbarung und Vernunft, Zurich 1961, S 156 vgl., ook Heb. 2:17; I Pet. 1:3. 
„Merkwaardig ook, zoals dese barmhartigheid Gods in het Oude Testament een heilshistorisch, eschatologisch begrip wordt. Waar Israël in die oude bedeling in zijn armoede en ellende met groot, hunkerend verlangen maar uitziet, is naar de waarachtig Barmhartige, in Wie God in die toekomst Zich aan Zijn bondsvolk openbaren zal en die in alle nood definitieve verlossing zal schaffen". ${ }^{5}$ ).

Die Kerk het as taak die Verkondiging, en die barmhartigheidsdiens is dan ook een van die verkondigingsgestaltes. Die gelowiges moet barmhartigheid betoon vanweë die barmhartigheid wat in Christus aan hulle betoon is: „Wees dan barmhartig soos julle Varder ook barmhartig is". ").

\section{ENKELE FASETTE VAN DIE BARMHARTIGHEIDSDIENS IN DIE OU TESTAMENT.}

Die barmhartigheidsdiens soos uitgebeeld in die Ou Testament is nie deur ' $n$ bepaalde orgaan verrig nie. Tog word die wortels vir die diens in die Ou Testament gevind. "). Reeds is daarop gewys dat die barmhartigheid van God verband hou met die verbond van God. Hy het die Verbond met Sy volk gesluit, hulle uit hul nood, veral in Egipte, uitgered. Hy is die Here hulle God. Deur Sy genade is hulle Sy volk en God kan van hulle gehoorsaamheid vra. ${ }^{8}$ ).

Die riglyne vir die barmhartigheidsbetoning is in verskillende wettiese voorskrifte gegee:

(a) Daar is die wette ingestel om armoede te voorkom. Ons kry bv. Lev. 25:36, 36: „En as jou broer by jou verarm en agterraak, moet jy hom ondersteun, soos 'n vreemdeling en bywoner dat hy by jou kan lewe. Jy moenie rente of wins van hom neem nie, maar jy moet jou God vrees, dat jou broer by jou kan lewe". ").

Talle ander wette kan ook onder hierdie afdeling gereken word, bv. 'n verdwaalde os of esel moet terugbesorg word ens. ${ }^{1 "}$ ).

5. G. Brillenburg Wurth, Gestalten der Liefde, Kampen, 1953, blz. 115.

6. Vergelyk ook bv. Math. 5:7; 12:7; 23:23; Luk. 10:37 en Jak. 2.13.

7. P. Biesterveld, J. van Lonkhuizen en R. J. W. Rudolph, Het Diaconaat, Hilversum 1907, Blz. $21-28$, H. D. A. du Toit, Olie op die Wonde, Pretoria, s.j. Bls. 15 .

8. Vgl. Deut. 7:6;14.2; 26:18, 27:9; Ex. 19:5 en G. van Rad, Theologies des Alten Testaments, bd. II Munchen 1962, S. 405, vgl. ook Lev. 25:23 v.v.

9. Biesterveld ea. a.w. bl. 27.

10. Ex. 23:3, 5. 
Wette is ook gemaak om te verseker dat die land onvervreembare eiendom van die familie bly. Dit het 'n bestaanswyse moontlik gemaak want Israel was by uitstek landbouers en veeboere. Jesaja keur dit af dat ,akker aan akker" gevoeg word totdat daar geen plek meer is vir ander nie. (5:8 vgl. Ook Miga 2:2). Voorsiening word ook gemaak dat grond wat deur die oorspronklike eienaar verloor is op billike wyse aan hom terugbesorg word of aan een van sy naasbestaandes wat vir hom intree. ").

(b) Besondere voorsorg word getref vir die weduwee en die wees. ${ }^{12}$ ).

Daar word gemaan dat hulle nie verdruk moet word nie en dat reg aan hulle moet geskied. Elke derde jaar moes 'n tiende van die inkomste afgestaan word vir die sorgbehoewendes. ${ }^{13}$ ) en 'n gedeelte van die sogenaamde Sabbatsjaar word ook daarvoor benut. ").

Die armes is nie onversorg gelaat nie. Terwyl die oes op die land ingesamel word, moes vir hulle voorsiening gemaak word deur die kant van die land nie af te oes nie. Dit is toegesê aan die armes en vreemdeling. ${ }^{15}$ ). Die are wat val,' is ook vir hulle bestem. Ook uit die wingerd word voorsiening gemaak vir die armes, weduwees en wese. ${ }^{1 k}$ ).

Die vreemdeling is ook toegelaat om van die druiwe van ' $n$ ander te eet of van die are in 'n land te pluk. Hy mag egter niks versamel van die druiwe om weg te neem nie, of 'n sekel in die graanlande gebruik nie. ${ }^{15}$ ).

Die armes word ook verder gehelp deurdat hy in die aand sy klere wat hy as pand gegee het, terug moet ontvang. Die kleed van die weduwee mag glad nie as pand geneem word nie. ${ }^{18}$ ). By die feesmaal moet ook vir die behoeftiges voorsiening gemaak word sodat almal vrolik kan wees op die fees. ${ }^{19}$ ).

In die profetiese prediking word ook aandag aan die barmhartigheidsdiens gègee. Dit berus egter in hoofsaak op die voorskrifte wat sy neerslag in die wettiese verkondiging gevind het

11. Deut. 25:5. Die lossing waarvan uitvoering in Rut berig word het dieselfde strekking.

12. Ons kan dit aflei van bv. Ex. 22:22; Deut. 19:18, Fx. 29:24 v.v.

13. Deut 14:29; 26:12.

14. Lev. $25: 2$ v.v.

15. Lev. 19:9, 10; 23.22; Deut. 24:19-21; Rut. 2:15, 16.

16. Lev. 19:10. Deut. 24:21

17. Deut. 23:24, 25.

18. Ex. 22:26; Deut. 24:6, 10, 12, 13, 17.

19. Deut. $16: 11,14$. 
en daarom is dit nie nodig om weereens ook daaraan aandag te gee nie. Dit gaan egter by die profete meer om die misstande wat ontstaan, omdat die barmhartigheidsdiens agterweë gebly het en die geregtigheid gruwelik vermink is. Veral kom dit sterk na vore by Amos. ${ }^{20}$ ).

Ons kan die volgende voorlopige konklusies maak:

(a) Die Here God is die Barmhartige. As Verbondsgod ontferm Hy Hom oor „Zijn arm en ellendige volk" en juis omdat Hy nie belangeloos staan teenoor die hulpbehoewende volk nie, onderskei dit Hom van die Afgode. ${ }^{21}$ ).

(b) Hulle moet die Here hulle God wat Sy Barmhartigheid aan hulle bewys het, liefhê met hul hele hart en siel en al hul krag. (Deut. 6:5). Omdat Hy die Here hulle God is, moet hulle hul naaste liefhê soos hulleself. (Lev. 19:18).

(c) Die betoning van barmhartigheid moet geskièd vanweë hulle liefde vir God en hulle naaste. Die eerste tafel van die dekaloog word dus nie gerieflikheidshalwe genegeer soos deur bv. die „Social Gospel” se aanhangers nie, maar, lê juis die grondslag van hierdie diens.

(d) Die versorging van die hulpbehoewendes is noodsaaklik sodat selfs voorskrifte gegee is hoedat voorsiening gemaak moet word.

(e) Betoning van barmhartigheid is nie vreemd in Israel nie. Dit is belangrik om daarop te let dat elkeen verantwoordelik is vir die diens en dat die sorg vir die behoeftiges nie aan enkelinge en belangstellendes oorgelaat is nie.

\section{BARMHARTIGHEIDSMOTIEWE IN DIE NUWE TESTAMENT.}

Die verhouding tussen God en mens is deur die mense verbreek en daarmee is die mens in die nood gedompel. Hierdie nood van die mens word deur Roscam Abbing ${ }^{22}$ ) as drie dimensioneel gesien, t.w. skuld, sonde en lyde. Die mens is dus skuldig, sondig en lydend.

Die straf vir die sonde kan ook nie uitbly nie $\left.{ }^{2 !}\right)$. As reg-

20. Vgl. bv. Amos 2:6-67; 4:1-3; 6:1-7 en die kommentaar van T. H. Robinson met S. Horst. Die Swoesf kleine Propheten, Tübingen 1954. (HAT) by die toenpaslike gedeeltes, vgl. ook F. C. Fensham, Geregtigheid in die boek Miga en parallelle uit die Nabye Ooste. Referaat gelewer by ge. leentheid van die Jaarvergadering van die afdeling Teologie I Julie 1965 P.U. vir C.H.O.

21. Dr. G. Brillenburg Wurth, Gestalten der liefde, Kampen 1953, blz. 114.

22. P. J. Roscam Abbing, Diakonia, Wageningen, s.j. Bladzy 5.

23. Heidelbergse Kategismus, Sondag IV. 
verdige God eis Sy geregtigheid dat die sonde vir die ewige straf aan liggaam en siel nie sal uitbly nie. Barmhartigheid aan die ellendige mens sal dus beteken dat vir hulle die straf op die sonde gedra word, want die mens is daartoe nie instaat nie. $\left.{ }^{24}\right)$. God het dit juis gedoen deur Sy Seun te gee om die straf namens, en in plek van die mensdom te dra. God het dit gedoen omdat hy die mens liefhet ${ }^{25}$ ). Hierdie liefde van God kom tot openbaring in Jesus Christus. Prof. B. J. Engelbrecht ${ }^{2 i}$ ) sluit by Roscam Abbing aan as hy skryf : „In Jesus Christus bewys God sy barmhartigheid aan die mense en wil Hy dat Sy liefde en barmhartigheid alreeds hier op aarde deurskemer, Sy medelye met ons lyding. Gods barmhartigheid vergeef nie net ons sondes nie, maar verlig ook ons lyding in hierdie wêreld, die lyding van ons geskapenheid, byvoorbeeld van ons broosheid, siekte en armoede". In Jesus Christus het ons toegang verkry tot die barmhartigheid van God soos dit blyk uit die groetformules wat Paulus gebruik het in sy briewe ${ }^{27}$ ).

As wesenskenmerk van die barmhartigheidsdiens van Jesus Christus kan gestel word dat $\mathrm{Hy}$,ons vlees en bloed” aangeneem het en die toorn van God op Hom geneem het, d.w.s. Hy het Homself ontledig en 'n dienskneggestalte aangeneem. Hy het gely omdat Hy met die mens medelye het. Vanweë Sy liefde is sondaars behou, en in Hom is daar redding sodat hulle nie verlore sal gaan nie ${ }^{28}$ ). Hy neem daarom die oorsaak van die lyding weg, naamlik die sonde. Hy het gekom om te soek en te red, die wat verlore is. ${ }^{29}$ ).

Vir Jesus Christus het dit egter nie net gegaan om die geestelike nood van die mens nie. Die liggaamlike nood het ewe-eens felkens Sy barmhartigheid ontlok. Dit sal ook verkeerd wees om die liggaamlike en geestelike "nooddruf" van die mens te skei. ${ }^{30}$ ).

Wanneer die blinde van Jerigo ${ }^{31}$ ) 'n beroep doen op die barmhartigheid van Jesus dan kry Hy hom jammer en sê : „Sien! Jou geloof het jou gered". Die genesing van die verlamde in Kapernaüm ${ }^{32}$ ) illustreer dieselfde as Jesus sê : „Seun hou goeie

24. Heidelbergse Kategismus S.V.

25. Johannes 3:16.

26. Professor B. J. Engelbrecht, Die Amp van die Diaken, Krugersdorp, 1957 , bls. 16.

27. Bv. I Tim 1:2; II Tim. 1:2.

28. P. J. Roscam Abbing, a.w. Blz. 358 gaan ook hierop in.

29. Vergelyk Biesterveld en ander a.w. blz. $33-34$.

30. Vgl. K. Dijk, de Dienst der Kerk, Kampen 1952, bl. 225.

31. Luk. 18:34-43 en Math. 20:29-34.

32. Math. 9:1-8. 
moed, jou sondes is jou vergewe". Jesus het elke keer die primêre oorsaak weggeneem van die noodlydende ${ }^{33}$ ).

Die werk van Jesus Christus kan eintlik saamgevat word onder die begrip „dien". Hy het nuwe betekenis gegee aan die begrip $\left.{ }^{34}\right)$. Dit kry 'n eervolle karakter in plek van die minderwaardige wat eers daaraan gegee is. Die dienswerk van Jesus Christus kan dan verstaan word soos Roscam Abbing :i) dit uiteensit : „Het woord dienst is inderdaad het meest geschikte woord om de belangrijkste elementen die het Christus gebeuren bepalen samenvattend te noemen. Het woord dienst opgevat als vrijwillige dienst van de een voor de ander, laat allereerst uitkomen dat de een de ander liefheeft. Het drukt voorts uit dat dit liefhebben inhoudt, dat de een de mindere wil zijn van de andere die hij dienen wil. Het zegt ten slotte dat dit liefhebben niet tot een gevoel beperk blijft, maar tot een konkrete daad komt. Liefde, zelfverlochening en daad schuilen in het woord dienst en daarom is het geschikt om aan te duiden, wat Hij deed die het Gode-gelijk-zijn niet als een roof heeft geacht, maar zichzelve ontledigd heeft en de gestalte van een diensknecht heeft aangenomen en den mensen gelijk is geworden. Hij die kwam nie om gediend te worden, maar om te dienen een in het midden van ons was als een die diende. In het woord dienst kan behalve de element en liefde, zelfverloochening en daad ook het element van gehoorzaamheid schuilen, in zoverre de dienst van de een aan de ander wel vrijwillig doch nietemin in opdracht van een derde geschieden kan. Ook dit element is terzake in die christologie, omdat die dienst van Christus als God en Zoon wel geheel vrijwillig was, als Zoon-mens en mens echter ook in gehoorzaamheid aan God geschiede. Het begrip ampt accentueert de gehoorzaamheid in die dienst". Bybelse fundering vind ons bv. in Luk. 22:27: „Maar Ek is onder julle soos een wat dien". ${ }^{36}$ ). Prof. B. J. Engelbrecht ${ }^{3 i}$ ) konkludeer juis uit die voorgaande : „Hy is dus die groot Diaken op wie se woorde en dade van diens alle egte diens en werklike diakenswerk gegrond is".

34. B. J. Engelbrecht a.w. Bl. 16.

35. P. J. Roscam Abbing a.w. Blz. 72.

36. Vgl. ook Luk. 12:35, 37. 

CHRISTUS :

Die barmhartigheidsdiens van Jesus Christus is nie veronderstel om beëindig te word met Sy hemelvaart nie. Uit die Heidelbergse Kategismus Sondag XXI vraag en antwoord 54, weet ons dat die Seun van God vir Hom 'n gemeente tot die ewige lewe uitverkies het en dat Hy dit ,beskerm en onderhou". Sy dienswerk word steeds voortgesit; soos Dijk dit stel: „dat Jezus Christus in deze bedeling werkt door Zijn Geest arbeid door het Woord, en dat dit Woord de kracht vormt van alle dienst in en door de Kerk". ${ }^{3 *}$ ).

Van die gelowiges word verwag om barmhartigheid te betoon ${ }^{34}$ ) en dit word hoog aangeslaan. ${ }^{4 \prime)}$.

Van kardinale belange vir die barmhartigheidsbetoning is Math. 22:37-39, die samevatting van die Wet. Uit die liefde vir God en vir die naaste kom die barmhartigheid na vore as synde die antwoord van die mens op die barmhartigheid van God "). Barmhartigheidsdiens moet altyd diens aan God wees. Aansluiting word gevind by Mat. 25:31-46. Die hulpbetoning en barmhartigheidsbewys word gedoen in die plek van Jesus Christus, in Sy naam, soos Hy dit gedoen het. Dit is diens aan mense, mense in nood, hongeriges en dorstiges, vreemdelinge, naaktes, siekes, gevangenes. Hier moet in gedagte gehou word dat : „Gott tritt der Welt gegenüber nicht als Herrscher, als Weiser, als Wissenschafter, als Fürst, Heerführer, oder Held, sondern in seinem Sohn als Knecht, als Sklave, als unser Bruder und nimt so unsere Schwachheit auf sich. Er wird derjenige, der sagen kann: Ich bin nackt gewesen, ich bin krank gewesen, ich bin gefangen gewesen, ich bin hungrig gewesen, ich bin tot gewesen. ${ }^{* 2}$ ).

Barmhartigheid word dan inherente deel van ons diens aan God. ${ }^{43}$ ).

Hier lê juis die probleem vir die aanhangers van die "Social Gospel". Die diens moet diens aan God bly. Daarom moet nie

37. B. J. Engelbrecht a.w. bl. 16.

38. K. Dijk, De Apostolische Kerk in haar Interne Dienste, opgeneem in De Apostolische Kerk, Kampen 1954, blz. 153. Vgl. ook Prof. A. D. Pont, Die Amp van die Diaken, in Die Hervormer, Jaargang Li. Nr. 8, Nov. 1960 , Bls. 6.

39. Lukas $6: 36 ; 10: 37$.

40. Mat. 5:7; 9:13.

41. J. Postma e.a. Die Diens van Barmhartigheid, Potchefstroom 1959, bl. 14.

42. Roland de Perry, Das Evangelium und die Zivilisationen opgeneem in Gottes Dienst-Menschenrienst. Zollikon 1958, S. 305.

43. Jak. 1:27. 
die mens en sy regte, vryheid, gelykheid of wat ook al in die middel staan nie, nie die beoefenaar van die barmhartigheid of die hulpbehoewende nie, maar steeds moet God die middelpunt van alle diens wees, alle diens is tot God gerig.

Wanneer die eerste deel van die samevatting van die Wet van sekondêre belang geag word, vind 'n geweldige verskraling van die diens van barmhartigheid plaas. Kostelik word dit deur Dijk uitgebeeld: „Wie stoffelijke steun biedt en de ellendige mens van geestelijke armoede laat omkomen zonder tot hem te spreken van de rijkdom der ontferming, die in Jesus Christus is, verwaarloost schroomelijk zijn roeping, en wie troost biedt aan de verslagenen van geest maar tegelijk geen hand uitsteekt om zulke verlorenen uit een sociale jammer op te heffen, is gelyk aan een, die een drenkeling een tractaatje, en geen stevig touw toewerpt." ${ }^{+4}$ ).

Die barmhartigheidsdiens moet gesien word in die lig van die priesterwerk van die gelowiges, wat sy verantwoordelikheid aanvaar vir sy naaste vanweë Sy liefde vir God en sy naaste. Achelis wil hierdie diens dan ook sien as die inwendige sending van die Kerk. ${ }^{4 i}$ ). Ons het in die Kerk altyd te make met 'n gemeenskap wat mekaar se laste moet dra.

Prof. A. D. Pont ${ }^{16}$ ) het daarop gewys dat die volk van Jesus Christus wat aan hom behoort, deur Hom regeer word deur Sy Gees en Woord, dit wil sê Jesus Christus regeer deur die ampte en die versorging of barmhartigheidswerk word juis aan die diakens opgedra. Sonder om 'n volledige uiteensetting te maak oor die begrip diakonos en aanverwante begrippe, kan daar net kortliks op gewys word dat in die woord die begrip ,diens" opgesluit is. Die Verlossingswerk van Jesus Christus is dienswerk. ${ }^{47}$ ). Dit is die grootste werk wat ooit gedoen is. Nou hang die hele dienswerk van die gemeente ten nouste hiermee saam. Die apostolaat waarin dit by uitstek gaan om die Verkondiging van die groot dade van God, is 'n diens. ${ }^{48}$ ).

Prediking is diakonia. $\left.{ }^{49}\right)$. Evangelisasiewerk, ${ }^{5 \prime}$ ) hulp met stoflike gawe is diakonia, "5) ja, al die werk in Christus se ge-

44. K. Dijk a.w. blz. 225 vgl. ook O. Haendler, Grundriss der Praktischen Theologie Berlin 1957, S.40.

45. E. C. Achelis, Praktische Theologie, Utrecht 1906, blz. 412 v.v.

46. A. D. Pont, Hervormer November 1960 bl. 6.

47. Vgl. Mark. 10:45 en Luk. 22:27.

48. Vgl. Hand. 1:17, 25; 20:24; 21:19; Rom. 11:13; 15; 31; II Kor. 4:1; 5:18; 6:3; I Tim. 1:12.

49. Hand. $6: 4$.

50. II Tim. 4:5.

51. Hand. $6: 1 ; 1: 29$; II Kor. $8: 4,9: 1 ; 12: 13$. 
meente is diakonia. Diakonos word genoem : Paulus ${ }^{52}$ ), Timotheus, ${ }^{33}$ ), Tichikus, ${ }^{54}$ ) en Ephras ${ }^{35}$ ).

Dit hou altyd verband met die werk van die gelowiges vir merkbaar bv. die bydrae wat Paulus van Macedonië en Achaje oorbring na Jerusalem, ${ }^{50}$ ) die verkondiging van die Evangelie aan die heidene. Die begrip Diakonia het inderdaad 'n ryke inhoud.

Die betoning van barmhartigheid in die Apostoliese Kerk het aanvanklik met 'n geweldige vaart begin. Die sg. eerste bekeerdes na die toespraak van Petrus op Pinksterdag, het hulle eiendomme en besitttings verkoop en die opbrengs is onder mekaar verdeel volgens die behoefte van elkeen. ${ }^{5 i}$ ). Met die geweldige groei ${ }^{5 x}$ ) wat die Kerk ondervind het, kon die Apostels blykbaar nie byhou om alles na behore te behartig nie en het die situasie ontstaan dat die Griekssprekende weduwees in die daaglikse versorging oor die hoof gesien is. ${ }^{5 v}$ ). Uit die nood wat so ontstaan het, is 'n nuwe situasie geskep en die Kerk moes aanpassings maak om dit te oorkom. Sewe (")) manne is gekies om hierdie diens van barmhartigheid voort te sit, of hulle as diakens gekies is, is nie nou ter sake nie ${ }^{61}$ ).

Paulus het opdrag gekry om te help voorsien in die nood van die arm Christene in Jerusalem ${ }^{62}$ ). Die gebrek kon ontstaan het deurdat alles aanvanklik uitgedeel ${ }^{\prime 3}$ ) is en nou vererger is deur die hongersnood. ${ }^{6 t}$ ). As Paulus nou hieroor aan die Korinthiërs skrywe, dan noem hy dit die liefdesdaad waardeur die egtheid van sulle liefde op die proef gestel word, (ii) en sê hy : „Want julle ken die liefde van onse Here Jesus Christus dat $\mathrm{Hy}$ alhoewel $\mathrm{Hy}$ ryk was, t.w.v. julle arm geword het, sodat julle deur Sy armoede ryk kan word" ${ }^{67}$ ).

52. I Kor. 3:5; II Kor. 3:6; 6:4; 11:23.

53. I Thes. 3:2; I Tim. 4:4.

54. Efes. 6:21; Kol. 4:7.

55. Kol. 1:7.

56. Rom. 15:25, 26.

57. Hand. $2: 44,45 ; 4: 32,34,35-37$.

58. Hand. $2: 41-47,4: 4,5: 14$.

59. Hand $6: 1$.

60. Hand. $6: 2$.

61. Dit is te betwyfel of die manne werklik as diakens gekies is. Die talle besware wat opduik teen so 'n eksegese is te oorwegend, vgl. $\mathrm{K}$. Dijk, Dienst der Kerk, bl. $240-241$. A. F. N. Lekkerkerker, Kanttekeningen bij het Hervormde Dienst boek, Deel IV Gravenhage 1956, Blz. 87 Prof. B. J. Engelbrecht a.w. bl. 24, Beyer T.W. z N.T. bd. II S.84.

62. Hand. $11: 28$.

63. R. P. Martin, Worship in the Early Church, London 1964 p. 78.

64. Hand $11: 28$.

65. II Kor. $8: 5$.

66. II Kor. $8: 8$.

67. II Kor. $8: 9$. 
Hulpverlening moet oor en weer geskied na gelang van die verwisseling in gebrek en oorvloed. ${ }^{68}$ ). Ons ontvang alles van God. "'). Ons is daarom net rentmeesters. Wanneer ons dan iets bydra dan moet dit vir ons ' $n$ dankoffer wees. ${ }^{70}$ ). Dit is nie alleen voorsiening in die behoeftes aan die heiliges nie, maar dit dra daartoe by dat God verheerlik sal word. ${ }^{i 1}$ ). In Rom. 12:13 word 'n direkte opdrag gegee : „Maak voorsiening in die behoeftes van die heiliges". Bydraes vir die noodlydendes in Jerusalem moet ook op geordende sistematiese wyse geskied; „Op elke eerste dag van die week moet elkeen van julle opsy sit en opspaar namate sy voorspoed is". ${ }^{2}$ ). God moet gedien word ook in die voorspoed van die ryke ${ }^{73}$ ) en hy moet vrygewig en mededeelsaam wees, dit is welbehaaglik by God. $\left.{ }^{{ }^{4}}\right)$. Ja, vergeet die weldadigheid nie en mededeelsaamheid nie, want God het 'n welbehae aan sulke offers" ${ }^{\circ 5}$ ). Goed moet gedoen word aan almal, maar insonderheid aan die geloofsgenote. ${ }^{76}$ ).

\section{SAMEVATTING :}

1. God het Sy barmhartigheid in Jesus Christus openbaar.

2. Jesus Christus het plaasvervangend vir ons gely en gesterwe.

3. Jesus Christus het in Sy barmhartigheid voorsien in die liggaamlike en geestelike nooddruf van die mens.

4. Die gelowiges kry opdrag om aan almal barmhartigheid te betoon, insonderheid aan die huisgenote van die geloof.

5. Oriënterend vir die diens van die Barmhartigheid is die samevatting van die Wet: „Jy moet die Here jou God liefhê .... en jou naaste soos jouself".

6. Barmhartigheidsbetoning is diens aan God. Dit moet geskied uit dankbaarheid en nie om enige verdienste by God te hê nie.

\section{BARMHARTIGHEIDSMOTIEWE IN DIE FORMULIER VIR} DIE. BEVESTIGING VAN DIAKENS.

In die bevestigingsformulier kom enkele motiewe na vore waarom die diens wel gedoen moet word. Die eerste wat ge-

68. II Kor. 8:14.

69. II Kor. $9: 10,11$.

70. II Kor. $9: 5$.

71. II Kor. $9: 13$.

72. I Kor. $16: 2$.

73. I Tim. $6: 17-19$.

74. Filip. $4: 18$

75. Heb. $13: 16$.

76. Gal. $6: 19$. 
noem word, is 'n verwysing na Hand. 4:34, 35. Die Apostels het die bediening van die armes waargeneem want die prys van wat verkoop is, is aan hulle toevertrou. Die gemeenskapsbesef het die Christene daartoe genoop om ook uit liefde alles te verkoop en Jesus Christus na te volg, om uit te deel aan diegene wat nie so goed voorsien was nie.

Die fundering word voortgesit deur te verwys na die weduwees van die Griekssprekende Jode wat onversorg gelaat is in die daaglikse versorging. Beyer ${ }^{i}$ ) het 'n heeltemal aanneemlike en interessante teorie: Vir hom gaan dit nie om die noodleniging nie maar om die gemeenskapsmaal. Die vraag wat opduik is dus: Is hierdie hellenistiese vroue tot die tafelgemeenskap toegelaat al dan nie? d.w.s. het hulle aan die gemeente behoort of nie. Die probleem kon ontstaan het uit die streng Joodse Wette en hul reinheidsbegrip. Daarom is hulle oorgedra aan sewe hellenistiese manne!

Is Beyer reg dan staan die motivering hier nie vas nie. Trouens die hele aangeleentheid van Hand. 6, sal baie deeglik nagegaan moet word alvorens dit aanvaar kan word as fundering vir die diakensamp.

Die diakens kry ook opdrag om die aalmoese vir die armes te versamel en te bewaar. Bybelse fundering kan gevind word in die voorbeeld van Paulus wat ook besig was om vir die behoeftiges van Judea in te samel. Martin ${ }^{i 8}$ ) sien hier 'n ou Joodse gebruik: „Every male Jew over the age of twenty years was required to contribute towards the maintenance of the Temple and is services. The money was collected at various centres and taken by responsible agents to the holy city. The term used in 2 Corinthians VIII, 23 is a context which is parallel with that in I Corinthians VI, 3 „messengers" (literally „Apostels”, ,delegates" from the Greek Apostoloi reproduces in Greek the exact word which was used of the Jewish officials whose task it was to collect and to bring in the Temple dues and the money for the support of the Rabbinate in Jerusalem".

Heel tereg word die versameling en bewaring van die aalmoese dus aan die diakens opgedra. In die praktyk beteken dit dat die aalmoese ingesamel word by die eredienste. Dit is egter maar 'n geringe deel van die fondse wat deur die diakens ingesamel word. Die taak van die diakens is 'n veelomvattende taak.

77. T.W.Z. N.T. Bd. II S84.

78. R. P. Martin a.w. Bl. 78.

79. Vergelyk Lekkerkerker a.w. bl. 98. 
Tereg wys Prof. A. D. Pont ${ }^{80}$ ) daarop dat: „die diens van die barmhartigheid wat deur die diaken verrig word is in wese die priesterlike-ontfermende optrede van die Kerk in die wêreld en dit vind sy agtergrond in die verkondiging van die genadige vergewing van die sonde deur Jesus Christus". Dit is die teologiese motief van die barmhartigheidsdiens en daarom moet die stoflike en uiterlike gifte aan die armes en noodydendes ook deur die vertroosting uit die Woord van God vergesel kan word.

\section{SLOTOPMERKING :}

Uit die voorgaande is dit duidelik dat die formulier nie voldoen aan die nodige motivering vir die barmhartigheidsdiens nie. Die ou formulier, wat deel uitmaak van die wat gebruik word vir die bevestiging van die ouderlinge sal egter nie sondermeer oorboord gegooi word nie. Dit is vir die Kerk 'n kosbare erfstuk waaraan daar ook bepaalde teologiese opvattings gekoppel word.

Alleenlik tot skade van die Kerk sal volhard word in die weiering vir die daarstelling van 'n bruikbare wisselformulier. Sonder om die Kerk vooruit te wil loop in die opstelling daarvan kan miskien gestel word dat in die wisselvorm die volgende aspekte beklemtoon sal moet word:

1. Die Here God het Hom in Ou en Nuwe Testament openbaar as die Barmhartige.

2. Jesus Christus het tydens Sy omwandelinge op aarde barmhartigheid betoon en voorsien in die liggaamlike en geestelike nooddruf van die mens.

3. Die gelowige word opgeroep tot betoning van barmhartigheid insonderheid teenoor die huisgenote van die geloof en aan almal in die algemeen.

4. Die barmhartigheid aan die opdrag van die Heer van die Kerk sodat hierdie diens altyd diens aan God sal wees.

D. J. Booysen.

80. A. D. Pont, Hervormer November 1960., bl. 7. 